\title{
Luminescent Ir(III) complexes bearing benzothiazole or benzoxazole-based pincer ligand
}

Junpei Kuwabara, ${ }^{a}$ Tomomi Namekawa, ${ }^{a}$ Eiko Sakabe, ${ }^{b}$ Masa-aki Haga, ${ }^{* b}$ Takaki Kanbara*a

${ }^{a}$ Tsukuba Research Center for Interdisciplinary Materials Science (TIMS), Graduate School of Pure and Applied Sciences, University of Tsukuba, 1-1-1, Tennodai, Tsukuba, Japan;

${ }^{b}$ Department of Applied Chemistry, Faculty of Science and Engineering, Chuo University, 1-13-27, Kasuga, Bunkyo-ku, Tokyo, Japan.

E-mail: mhaga@kc.chuo-u.ac.jp; kanbara@ims.tsukuba.ac.jp

\begin{abstract}
Ir complexes bearing pincer ligands are expected to be efficient phosphorescent materials. This work investigated the solid-state structures and photophysical properties of $\operatorname{Ir}(\mathrm{III})$ complexes that contain different $\mathrm{NCN}$ pincer ligands $(\mathrm{NCN}=$ 1,3-bis(2-benzothiazolyl)benzene, 1,3-bis(2benzoxazoyl)benzene, or 1,3-bis(2-benzimidazoyl)benzene derivatives), bidentate cyclometalating NC ligands ( $\mathrm{NC}=2$-phenylpyridine or 2-phenylbenzothiazole), and anionic ancillary ligands. The structure of the NCN pincer ligands is a dominant factor for determining the emission wavelength, rather than the bidentate NC and ancillary ligands. The organic light emitting diodes (OLEDs) with an Ir(III) complex show electroluminescence with $14 \%$ external quantum efficiency at $1 \mathrm{mAcm}^{-2}$. Modification of the device structure improved the efficiency at the high current density region.
\end{abstract}

Keywords: Pincer complex; Photoluminescence; Electroluminescence; Ir(III) complex; OLEDs.

\section{Introduction}

Cyclometalating tridentate ligands (so-called pincer ligands) provide high stability, unique catalytic activity, and efficient luminescent properties to transition-metal complexes [1-5]. Nitrogen-based $\mathrm{NCN}$ and $\mathrm{CNN}$ pincer ligands have been used to develop Pt complexes showing highly efficient phosphorescence [2,6]. Williams and Haga independently developed Ir complexes bearing NCN pincer ligands [7-14], although bidentate ligands such as 2-phenylpyridine and 2-phenylbenzothiazole were 
typically used as cyclometalating ligands for emissive Ir complexes [15-17]. Owing to their high thermal stability and emission quantum efficiency [18-20], pincer Ir complexes are expected to be used as an emissive material for organic light emitting diodes (OLEDs) [21-25]. We previously reported an Ir(III) complex bearing a benzothiazole-based NCN pincer ligand (Complex 1, Fig. 1) [22]. Complex 1 showed high quantum yield (89\%) and performed well as an emissive material for OLEDs. To gain a further understanding of benzothiazole-based NCN pincer Ir complexes, their ligand effects were evaluated in this study. We focused on the structure of the pincer ligand ( $\mathrm{R}$ and benzothiazole/benzoxazole), a bidentate NC ligand, and an anionic ancillary ligand (Y) (Fig. 1). For evaluating the effects of these ligands on the solid-state structures and physical properties, five Ir complexes were synthesized. Herein, we report the structure and physical properties of the Ir complexes and electrophosphorescent properties in OLEDs.
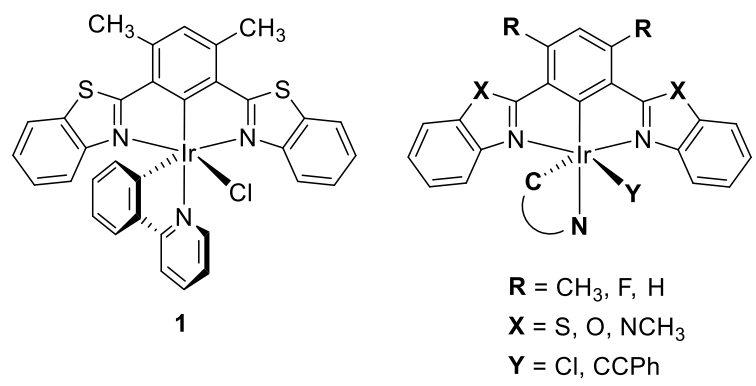

Fig. 1. Structure of the benzothiazole, benzoxazole, or benzimidazole-based pincer Ir complex.

\section{Results and discussion}

\subsection{Synthesis of the Ir complexes}

Ir complex 1 and 7 were prepared by a reported method (Scheme 1) [12,22]. In a similar way, Fsubstituted complex $\mathbf{2}$ was synthesized as follows. The fluorine-substituted NCN ligand $\left(\mathbf{L}_{\mathbf{F}-\mathbf{H})}\right.$ was prepared by the Suzuki-Miyaura cross coupling reaction (see the Experimental section). The reaction of $\mathrm{IrCl}_{3} \cdot \mathrm{nH}_{2} \mathrm{O}$ and $\mathbf{L}^{\mathbf{S}} \mathbf{F}-\mathbf{H}$ at $100{ }^{\circ} \mathrm{C}$ afforded the corresponding Cl-bridged dinuclear complex, $\left[\operatorname{Ir}\left(\mathbf{L}_{\mathbf{F}} \mathbf{S}_{\mathbf{2}} \mathbf{C l}_{\mathbf{2}}\right]_{2}\right.$. In the final step, a microwave-assisted cyclometalation reaction of 2-phenylpyridine for 4 min afforded the target complex 2 in $43 \%$ yield. The effect of the microwave-assisted reaction was confirmed by the fact that the reaction under conventional heating afforded only $13 \%$ yield with $24-\mathrm{h}$

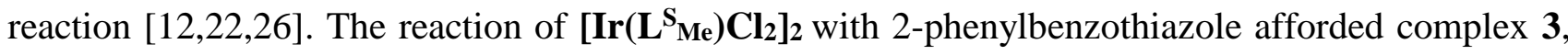


bearing the cyclometalating phenylbenzothiazole ligand. Complex 4 was obtained via abstraction of the $\mathrm{Cl}$ ligand of $\mathbf{1}$ by silver trifluoromethanesulfonate (AgOTf) and a subsequent reaction with potassium phenylacetylide. When the pincer ligand contained an unsubstituted phenyl group $(\mathrm{R}=\mathrm{H})$,

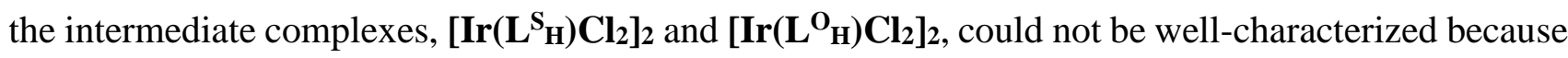
of low solubility of these complexes, and unidentified side products which might be formed through $\mathrm{C}-\mathrm{H}$ bond cleavage at an undesired position. Without protection groups $(\mathrm{R})$ in the central phenyl ring, two orthometalation pathways might be possible, which make the reaction complicated. A similar side reaction has already been pointed out by Williams [7]. The reaction of these intermediates with 2phenylpyridine under the microwave irradiation conditions afforded the corresponding complex (5 or 6) and side products, which could be separated by silica-gel column chromatography. Products $\mathbf{5}$ and $\mathbf{6}$ were further purified by recrystallization, thereby the yield was very low.

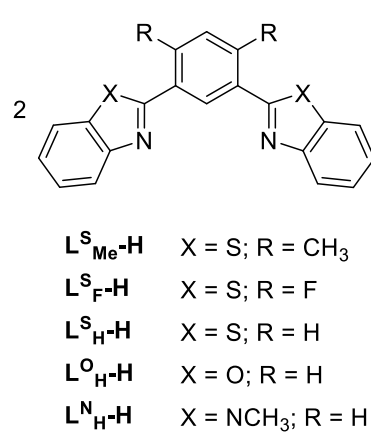

$\mathrm{L}^{\mathrm{N}} \mathrm{H}^{-\mathrm{H}} \quad \mathrm{X}=\mathrm{NCH}_{3} ; \mathrm{R}=\mathrm{H}$

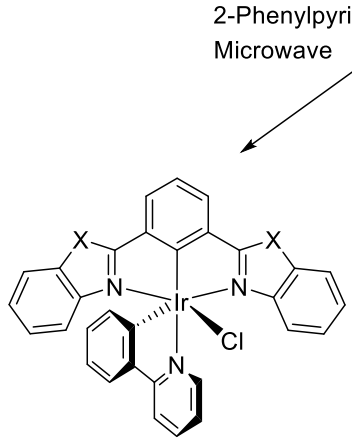

$5 \times=S$

$6 \mathrm{X}=\mathrm{O}$

$7 \mathrm{X}=\mathrm{NCH}_{3}$
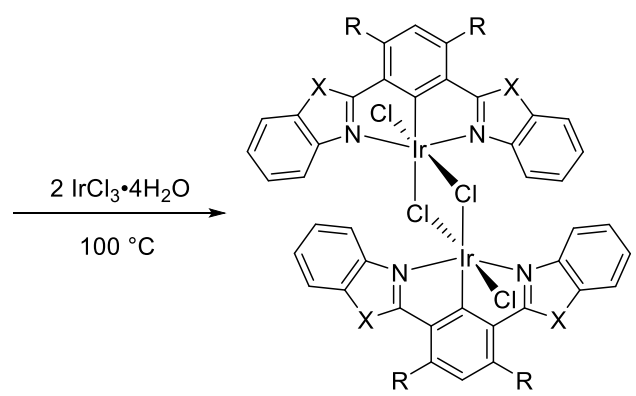

$\left[\operatorname{lr}\left(\mathrm{LS}^{\mathrm{S}}{ }_{\mathrm{Me}}\right) \mathrm{Cl}_{2}\right]_{2}$

$\left[\operatorname{lr}\left(\mathrm{LS}_{\mathrm{F}}\right) \mathrm{Cl}_{2}\right]_{2}$

$\left[\operatorname{lr}\left(\mathrm{LS}_{\mathrm{H}}^{\mathrm{S}}\right) \mathrm{Cl}_{2}\right]_{2}$

$\left[\operatorname{lr}\left(\mathrm{L}^{\mathrm{O}}{ }_{\mathrm{H}}\right) \mathrm{Cl}_{2}\right]_{2}$

$\left[\operatorname{lr}\left(\mathrm{L}^{\mathrm{N}}{ }_{\mathrm{H}}\right) \mathrm{Cl}_{2}\right]_{2}$
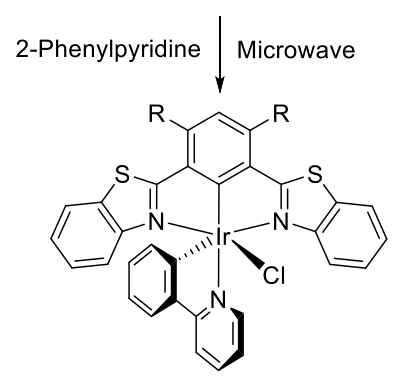

$1 \mathrm{R}=\mathrm{CH}_{3}$

$2 \mathrm{R}=\mathrm{F}$
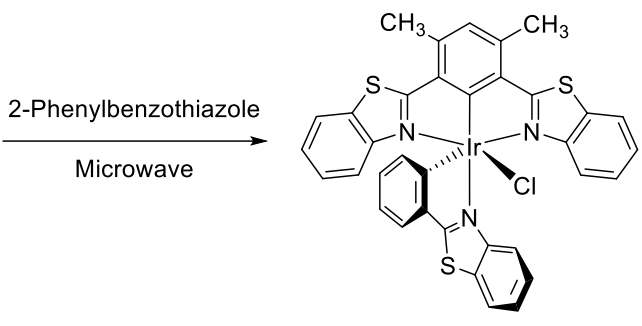

3
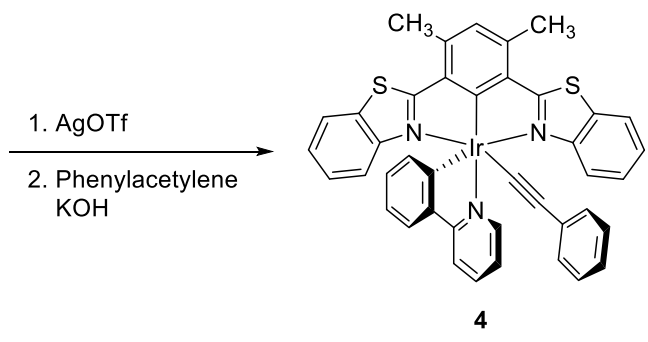

Scheme 1. Synthesis of the Ir complexes 1 - 7 [12,22]. 


\subsection{Crystal structures of complexes}

The solid-state structures of complexes $2,3,4$, and $\mathbf{6}$ were determined by X-ray diffraction studies (Fig. 2 and Fig. S1 in the supporting information). All structures revealed a distorted octahedral geometry around the Ir center. The cyclometalating carbon in the bidentate ligand (C2) is located at the trans position to the $\mathrm{Cl}$ or acetylido ligand, which is consistent with the structure of complex 1 [22] and the related Ir complexes $[23,26]$. Table 1 shows the representative bond lengths of complexes $\mathbf{2}-$ $\mathbf{4}$, accompanied with the reported data of $\mathbf{1}$ for comparison [22]. Complex $\mathbf{3}$ has the shortest $\operatorname{Ir} 1-\mathrm{C} 1$ bond length, presumably due to the weak trans influence of the bidentate phenylbenzothiazole ligand, which is consistent with the longest Ir1-N3 bond in 3. The long Ir1-N3 bond would be caused by the steric repulsion between the $\mathrm{Cl}$ ligand and the $\mathrm{C}-\mathrm{H}$ bond at position 4 in the phenylbenzothiazole ligand (Fig. S2). This steric demand is a typical feature of the phenylbenzothiazole ligand, in contrast to the phenylpyridine ligand. Complex 4 has a characteristically long Ir1-C2 bond, presumably due to the strong trans influence of the phenylacetylido ligand.
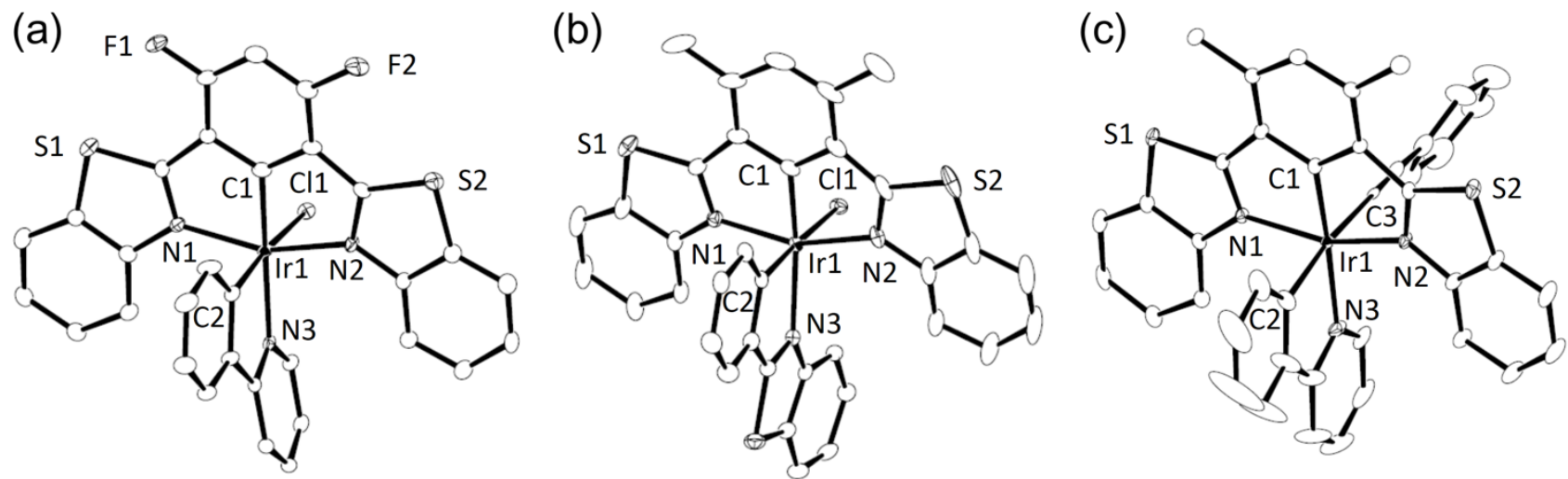

Fig. 2. Crystal structures of (a) 2, (b) 3, and (c) 4. Hydrogen atoms and solvating molecules are omitted for clarity. The thermal ellipsoids are at the $30 \%$ levels.

Table 1 Selected Bond Distances $(\AA)$.

\begin{tabular}{ccccccc}
\hline & $\mathrm{Ir} 1-\mathrm{C} 1$ & $\mathrm{Ir} 1-\mathrm{C} 2$ & $\mathrm{Ir}-\mathrm{C} 11$ & $\mathrm{Ir}-\mathrm{N} 1$ & $\mathrm{Ir}-\mathrm{N} 2$ & $\mathrm{Ir}-\mathrm{N} 3$ \\
\hline $\mathbf{1}^{\mathrm{a}}$ & $1.956(6)$ & $2.013(7)$ & $2.5034(15)$ & $2.073(6)$ & $2.083(7)$ & $2.158(5)$ \\
$\mathbf{2}$ & $1.934(6)$ & $1.996(7)$ & $2.4533(16)$ & $2.073(5)$ & $2.090(5)$ & $2.157(5)$ \\
$\mathbf{3}$ & $1.9177(4)$ & $2.0197(4)$ & $2.4589(5)$ & $2.0625(4)$ & $2.0595(3)$ & $2.2246(4)$ \\
$\mathbf{4}$ & $1.932(6)$ & $2.049(6)$ & & $2.075(5)$ & $2.073(4)$ & $2.154(6)$ \\
\hline
\end{tabular}

${ }^{a}$ Reported in reference [22]. 


\subsection{Physical properties}

Complex 1 has a high thermal stability; the 5\% decomposition temperature of 1 was $480{ }^{\circ} \mathrm{C}$ [22], which proves to be the advantage of the pincer ligand. Table 2 summarizes physical properties of 1-6, together with the reported data of $\mathbf{7}$ for comparison. Electrochemical behaviors of the complexes were investigated by cyclic voltammetry using a ferrocenium/ferrocene $\left(\mathrm{Fc}^{+} / \mathrm{Fc}\right)$ redox couple as a referece. Because the cyclic voltammograms of $\mathbf{1 - 4}$ reveal some quasi-reversible or irreversible oxidation and reduction waves, the peak potentials for oxidation and reduction were used for comparison. Complex 4 has an especially low oxidation potential $\left(E^{\mathrm{ox}}=0.55 \mathrm{~V}\right)$ for $\operatorname{Ir}(\mathrm{III} / \mathrm{IV})$, presumably due to the strong electron-donating nature of the phenylacetylido ligand. This property agrees with the strong trans influence observed in the solid-state structure. Complex 2 is more readily reduced $\left(\mathrm{E}_{\mathrm{p}}{ }^{\text {red }}=-2.02 \mathrm{~V}\right)$ than 1. This result indicates that the F substituents lower the LUMO level of the complex. To confirm this, density functional theory (DFT) calculations were performed at the B3PW91 level with the LANL2DZ basis set (Fig. S3). The LUMO of complex $\mathbf{2}$ is mainly located on the F-substituted NCN pincer ligand. In addition, the energy level of the LUMO of $\mathbf{2}$ is lower than that of $\mathbf{1}$. These calculation results explain that the F substituents lower the energy level of the LUMO on the pincer ligand. A comparison in 5-7 affords information concerning the $\mathrm{X}$ groups in the NCN ligand. Complex $\mathbf{7}$ bearing the benzimidazole-based ligand showed the lowest oxidation and reduction potential, which reflects the electron donating property of the $\mathrm{NCH}_{3}$ moiety, compared to benzoxazole and benzothiazole. Complexes 5 and $\mathbf{6}$ showed the reduction potentials at -1.99 and $-2.04 \mathrm{~V}$, respectively, which indicates that $\mathrm{L}_{\mathrm{H}}^{\mathrm{S}}$ and $\mathrm{L}_{\mathrm{H}}^{\mathrm{O}}$ ligands possess lower $\pi^{*}$ orbital energies, compared to that of $\mathrm{L}^{\mathrm{N}} \mathrm{H}$. As a result, benzoxazole and benzothiazole substituents serve as a stronger $\pi$-accepting groups, and the electrochemical measurements afforded the HOMO/LUMO gap: 5 (2.73 eV), 6 (2.83 eV), and 7 (2.88 $\mathrm{eV})$. 
Table 2 Physical properties of 1-7.

\begin{tabular}{cccccccc}
\hline Complex & $\begin{array}{c}E_{\mathrm{p}}{ }^{\text {ox }} \text { or } E^{1 / 2 \mathrm{a}} \\
\left(\Delta E_{\mathrm{p}}{ }^{\mathrm{c}}\right) / \mathrm{V}\end{array}$ & $\begin{array}{c}E_{\mathrm{p}}{ }^{\mathrm{red}} \text { or } E^{1 / 2 \mathrm{~b}} \\
\left(\Delta E_{\mathrm{p}}{ }^{\mathrm{c}}\right) / \mathrm{V}\end{array}$ & $\begin{array}{c}\lambda_{\mathrm{em}}{ }^{\mathrm{d}} \\
/ \mathrm{nm}\end{array}$ & $\Phi^{\mathrm{e}}$ & $\tau^{\mathrm{f}}$ & $k_{\mathrm{r}}{ }^{\mathrm{g}}$ & $k_{n \mathrm{r}}{ }^{\mathrm{h}}$ \\
\hline $\mathbf{1}^{\mathrm{i}}$ & 0.74 & -2.23 & 572 & 0.89 & 1.9 & 46 & 5.7 \\
$\mathbf{2}$ & 0.87 & -2.02 & 557 & 0.15 & 0.39 & 38 & 220 \\
$\mathbf{3}$ & 0.82 & -2.16 & 569 & 0.85 & 2.2 & 38 & 6.7 \\
$\mathbf{4}$ & 0.55 & -2.22 & 572 & 0.29 & 1.9 & 16 & 39 \\
$\mathbf{5}$ & $0.74(100)$ & $-1.99(100)$ & 588 & 0.50 & 1.1 & 25 & 25 \\
$\mathbf{6}$ & $0.79(110)$ & $-2.04(100)$ & 576 & 0.66 & 2.1 & 31 & 16 \\
$\mathbf{7}^{\mathrm{j}}$ & $0.42(60)$ & $-2.46(66)$ & 555 & 0.78 & 1.78 & 44 & 12 \\
\hline
\end{tabular}

${ }^{\mathrm{a}}$ Peak or half-wave potential for oxidation, ${ }^{\mathrm{b}}$ Peak or half-wave potential for reduction, ${ }^{\mathrm{c}}$ Peak separation between anodic and cathodic peaks as $\mathrm{mV}$, ${ }^{\mathrm{d}}$ Maximum emission wavelength recorded in degassed solution in $\mathrm{CH}_{2} \mathrm{Cl}_{2}$ at $20 \mu \mathrm{M}$ at room temperature, ${ }^{\mathrm{e}}$ Absolute quantum yield, ${ }^{\mathrm{f}}$ The lifetime of emission; $\lambda_{\mathrm{ex}}=374 \mathrm{~nm},{ }^{\mathrm{g}}$ Radiative rate constant, ${ }^{\mathrm{h}}$ Non-radiative rate constant, ${ }^{\mathrm{i}}$ Reported in reference [22], ${ }^{\mathrm{j}}$ Reported in reference [12].

Figure 3 reveals the absorption and photoluminescence spectra of the complexes in the solution state. Complexes 1-4 show absorptions at around $450 \mathrm{~nm}$ as the longest-wavelength absorption (Fig. 3a). Time-dependent (TD) DFT calculations show that these absorptions correspond to transitions from HOMO to LUMO and HOMO-1 to LUMO (Fig. S3). HOMO and HOMO-1 in 1-3 mainly locate on the Ir center and LUMO locates on the NCN ligand. Therefore, metal to ligand charge transfer (MLCT) is a reasonable assignment for absorption in $\mathbf{1 - 3}$, which agrees with the reported assignment for the pincer Ir complexes $[23,26]$. In the case of $\mathbf{4}$, contribution of the phenylacetylido ligand to HOMO and HOMO-1 was observed (Fig. S3). The MLCT and interligand charge transfer should be mixed in the broad absorption of 4 [10]. Absorption of 4 appears in the long wavelength-region presumably due to the contribution of the interligand charge transfer. In contrast to the similar absorption of $\mathbf{1}$ and $\mathbf{3}$, absorption onset of 2 appears at the short-wavelength region, showing a wide HOMO/LUMO gap. The low LUMO level, confirmed through CV and DFT analyses, and the wide HOMO/LUMO gap of 2 indicate that the F substituents also lower the energy level of the HOMO, which locates on the Ir center. 

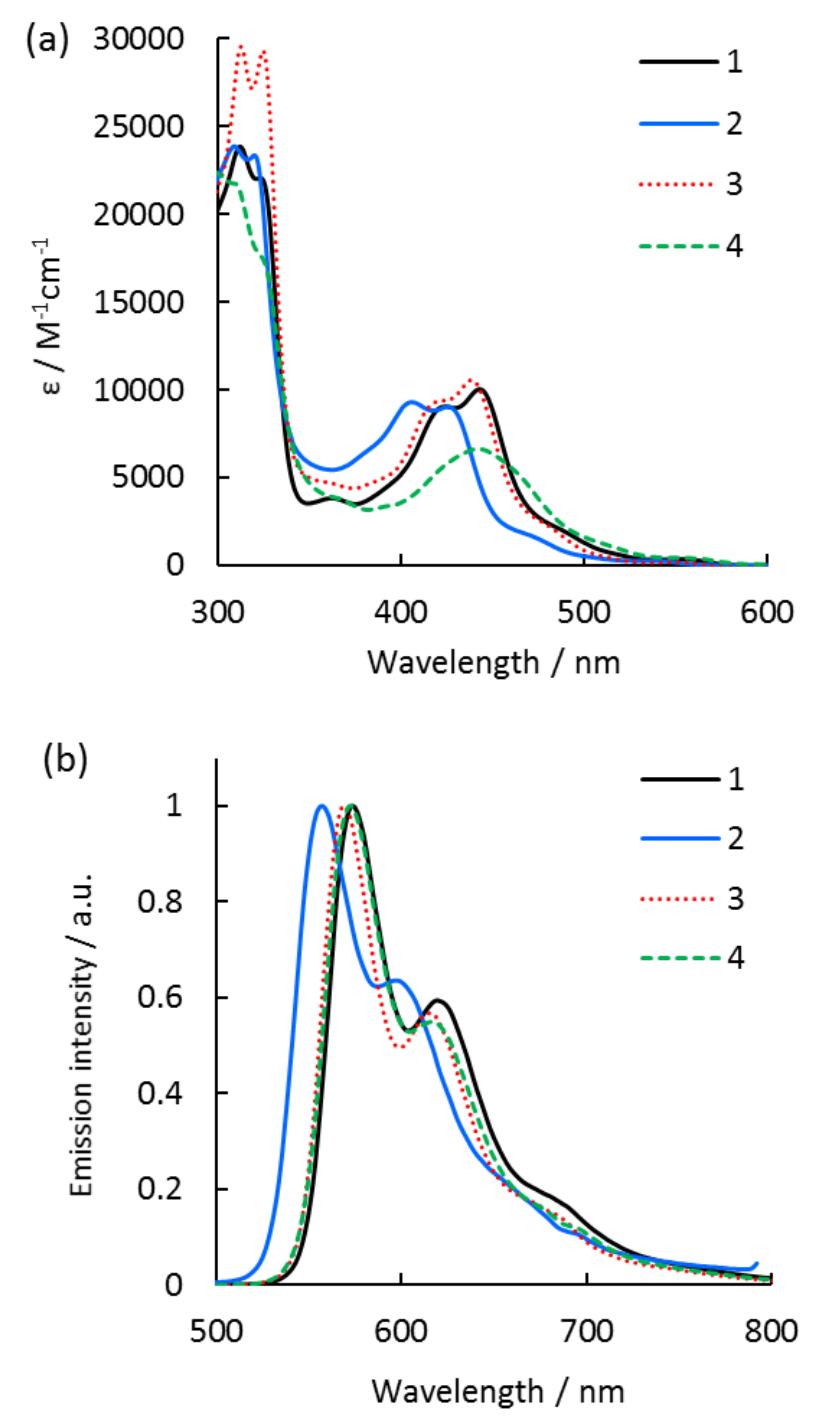

Fig. 3. (a) UV/Vis absorption and (b) photoluminescence spectra of $\mathbf{1 - 4}$ in $\mathrm{CH}_{2} \mathrm{Cl}_{2}$ at r.t. 
The photoluminescence spectra show similar vibrational structures to each other (Fig. 3b). Complex 2 reveals short-wavelength emission, in contrast to other complexes. This means that the structure of the NCN ligand is a dominant factor for modulating the emission wavelength, rather than the NC bidentate and anionic ancillary ligands. Moreover, the emission wavelenghth depends on the $\mathrm{X}$ group in the NCN ligand; the emission maximum shifted to a longer wavelength in the order: $\mathrm{NCH}_{3}(\mathbf{7})<\mathrm{O}(\mathbf{6})<$ S (5) [12] (Fig. 4). This order is consistent with the HOMO/LUMO gap estimated from the electrochemical measurements: $\mathrm{NCH}_{3}(2.88 \mathrm{eV})>\mathrm{O}(2.83 \mathrm{eV})>\mathrm{S}(2.73 \mathrm{eV})$. The value of the $\mathrm{HOMO} / \mathrm{LUMO}$ gap is mainly affected by the LUMO level, $\mathrm{NCH}_{3}(-2.37 \mathrm{eV})>\mathrm{O}(-2.76 \mathrm{eV})>\mathrm{S}(-$ $2.81 \mathrm{eV}$ ) although the both HOMO and LUMO levels were affected by the X groups (Fig. S6). The LUMO level is more sensitive to the $\mathrm{X}$ groups than the HOMO level presumably due to the large contribution of the NCN ligand on the LUMO (Fig. S5). The less electron donating property of the X group would stabilize the enegy level of NCN ligand (LUMO) and make the HOMO/LUMO gap narrower. In terms of the $\mathrm{R}$ group, the emission maximum shifted to a longer wavelength in the order: $\mathrm{F}(\mathbf{2})<\mathrm{CH}_{3}(\mathbf{1})<\mathrm{H}(\mathbf{5})($ Table 1). This order is not simply explained by electrical propety of the substituents becuse the substituents on the NCN ligand affect both the LUMO and HOMO levels, which were confiermed through the DFT calculations. The quantum yield of complex $\mathbf{2}$ is as low as 0.15, whereas those of $\mathbf{1}$ and $\mathbf{3}$ are 0.89 and 0.85 , respectively. Owing to the high non-radiative decay constant of $\mathbf{2}$, the F substituents in $\mathbf{2}$ may cause a non-radiative pass (Table 2). Williams also reported a relatively low quantum yield of an Ir complex bearing a F-substituted NCN pincer ligand [23].

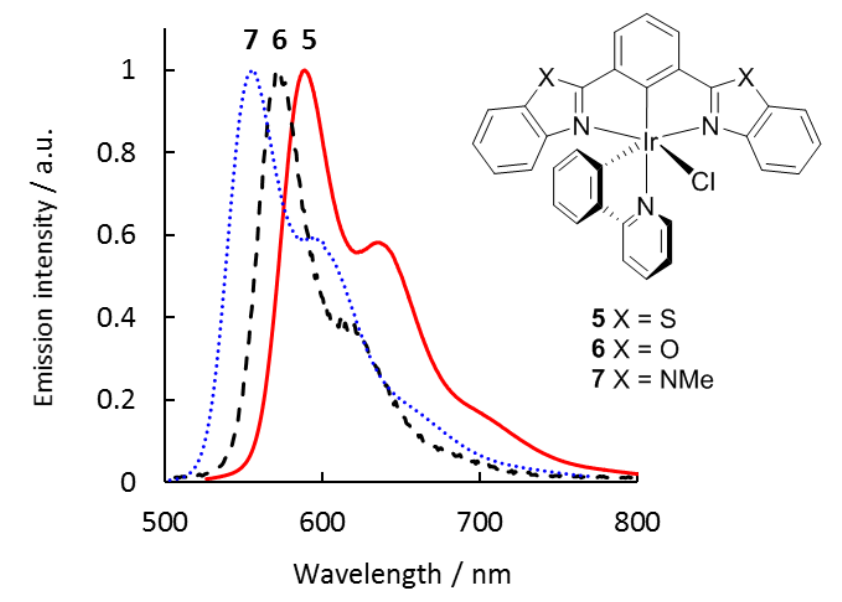

Fig. 4. Photoluminescence spectra of $5-7$ in $\mathrm{CH}_{2} \mathrm{Cl}_{2}$ at r.t. 


\subsection{Electroluminescence properties}

Complex 1 has the highest photoluminescence quantum yield among the synthesized complexes, thus complex 1 was evaluated as a dopant for the emitting layer of OLEDs. Previously, we reported OLEDs with an emitting layer composed of $\mathbf{1}$ and bis(2-methyl-8quinolinolato)(phenolato)aluminum(III) (BAlq) as the host material (Fig. 5, device I) [22]. In this study, a modified device (device II) was fabricated to improve the efficiency. Device II has a double emitting layer structure composed of $1 / \mathrm{BAlq}$ and $\mathbf{1} / \mathrm{NPB} \quad\left(\mathrm{NPB}=N, N^{\prime}\right.$-bis(naphthalen-1-yl)- $N, N^{\prime}-$ bis(phenyl)benzidine). Because NPB is a hole transporting material, this double layer is expected to improve the recombination efficiency in the emitting layer. The electroluminescence spectra of devices I and II are similar to each other (Fig. 5a). Because these electroluminescence spectra are quite similar to the photoluminescence spectrum of $\mathbf{1}$ in the diluted solution state, $\mathbf{1}$ was well dispersed throughout the host materials. The turn-on voltage of device II was $3.3 \mathrm{~V}$, and the brightness of the device reached to $320 \mathrm{~cd} / \mathrm{m}^{2}$ at at $1 \mathrm{mAcm}{ }^{-2}$. The coordinates of the CIE chromaticity of device II were $x=0.57$ and $y=0.43$ at $1 \mathrm{mAcm}^{-2}$. Although the external quantum efficiency of device II is almost the same as that of device I (14\%) at a low current density of $1 \mathrm{mAcm}^{-2}$, the efficiency roll-off improved (Fig. 5b). This result shows that the double layer structure promotes efficient recombination in the emitting layer even at the high-current density region. 

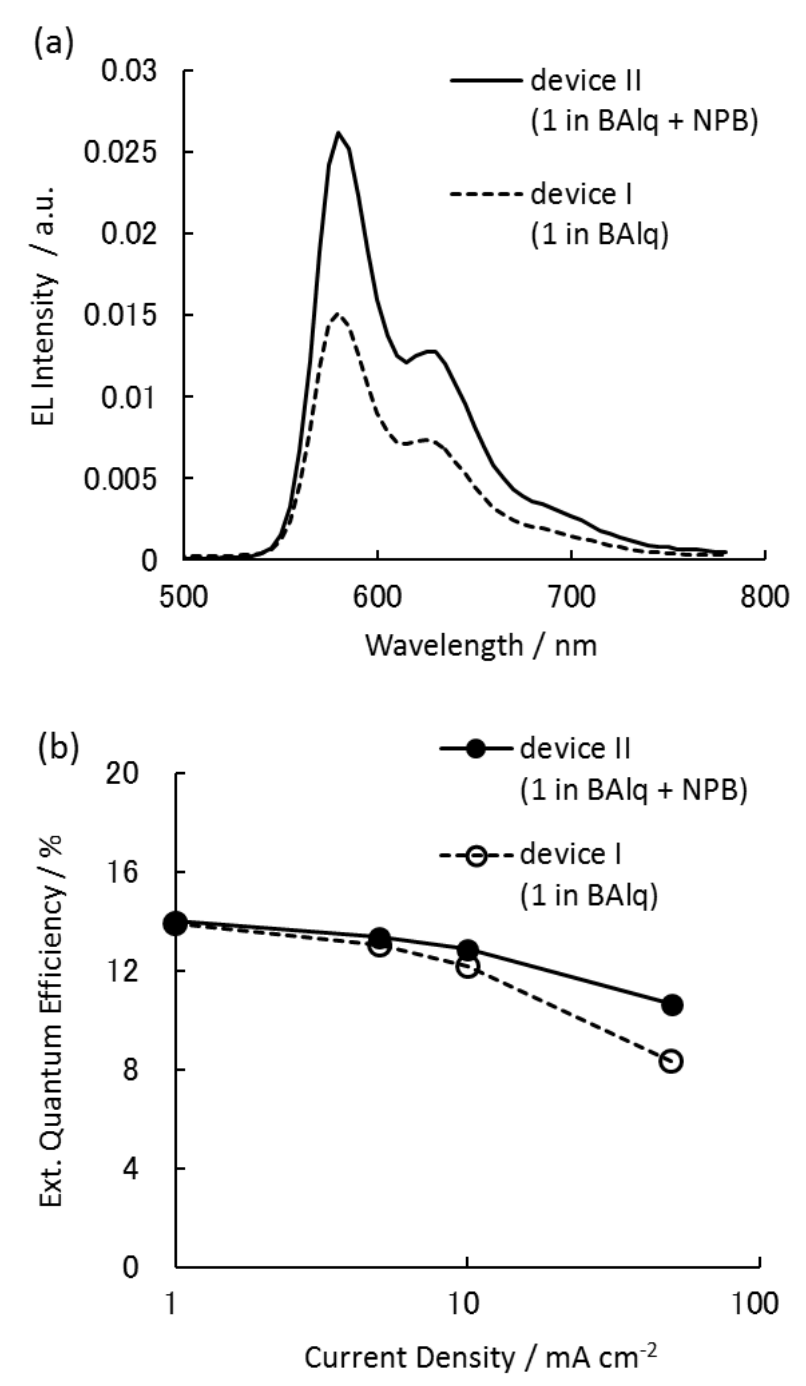

Fig. 5. (a) Electroluminescence spectrum of device I (dashed line) and II (solid line). (b) External quantum efficiencies of devices I (open circle) and II (filled circle).

\section{Conclusions}

Ir(III) complexes with different NCN pincer ligands were synthesized and evaluated in terms of their solid-state structures and photophysical properties. The structure of the NCN pincer ligands is a dominant factor for determining the emission wavelength. The electron-withdrawing F substituents on the benzothiazole-based pincer ligand induced a blue shift of emission and lowered the photoluminescence quantum yield, compared to that of the methyl substituents. In addition, the benzoxazole-based pincer complex showed a blue shift of the emission of the benzothiazole-based pincer complex. The alternation of the bidentate cyclometalating NC ligand from phenylpyridine to phenylbenzothiazole induced a negligible change in the emission properties. In terms of the anionic 
ancillary ligand, a $\mathrm{Cl}$ ligand provided higher quantum efficiency than a phenylacetylido ligand in the present case. OLEDs with the Ir complex show electroluminescence with $14 \%$ external quantum efficiency at $1 \mathrm{mAcm}^{-2}$. The modification of the device structure of the OLEDs improved the efficiency at the high current density region. These fundamental insights provide the principle for the molecular design of pincer Ir complexes as efficient emissive materials.

\section{Experimental}

\subsection{General}

${ }^{1} \mathrm{H},{ }^{13} \mathrm{C}\left\{{ }^{1} \mathrm{H}\right\}$, and ${ }^{19} \mathrm{~F}$ NMR spectra were recorded on a JEOL ESC-400 and a Bruker AVANCE 400 NMR spectrometer. ESI Mass spectra were recorded on a Applied Biosystems Qstar Pulsar I. Elemental analyses were carried out with a Perkin-Elmer 2400 CHN Elemental Analyzer. The UV/Vis absorption spectra were measured with a JASCO V-630 spectrophotometer. To measure the PL characteristics of the complexes in the solution state, the dissolved oxygen in the solution was removed by bubbling with $\mathrm{N}_{2}$ for $20 \mathrm{~min}$. The emission spectra at room temperature were measured with a JASCO FP-6200 spectrophotometer. The quantum yields at room temperature were measured by an absolute PL quantum yield measurement system (C9920-02, Hamamatsu photonics k.k.). DFT calculations were performed at the B3PW91 level with the LANL2DZ basis set implemented in Gaussian 09 programs suits. The details for device structure of OLEDs were described in supporting information. Emission lifetimes were determined by the same method as described previously $[11,12]$. $\mathrm{Pd}\left(\mathrm{PPh}_{3}\right)_{4}$ was purchased from Kanto and stored under nitrogen atmosphere. 2-Chlorobenzothiazole and 2-phenylpyridine were purchased from Aldrich. 2-Phenylbenzothiazole, phenylacetylene, and other chemicals were purchased from Tokyo Chemical Industry (TCI). 4,6-Difluorobenzene-1,3-

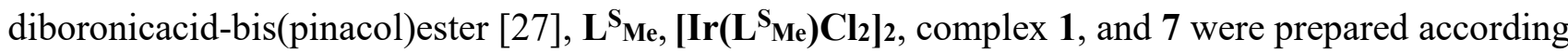
to the literature method [22].

\subsection{Crystal structure determination}

Intensity data were collected on a Bruker SMART APEX II ULTRA or Rigaku Mercury70 with Mo$K \alpha$ radiation (Table 3). A full matrix least-squares refinement was used for non-hydrogen atoms with an anisotropic thermal parameters method. Hydrogen atoms were placed at the calculated positions 
and were included in the structure calculation without further refinement of the parameters. CCDC1529374 for $\mathbf{2}, 1529375$ for $\mathbf{3}, 1529376$ for $\mathbf{4}$, and 1529377 for $\mathbf{6}$ contain the supplementary crystallographic data for this paper. These data can be obtained free of charge from The Cambridge Crystallographic Data Centre via www.ccdc.cam.ac.uk/data_request/cif.

\subsection{Electrochemical measurement}

Electrochemical measurements were carried out with a standard three-electrode configuration. tetrabutylammonium hexafluorophosphate $\left(\mathrm{Bu}_{4} \mathrm{NPF}_{6}\right)$ or tetrabutylammonium tetrafluoroborate $\left(\mathrm{Bu}_{4} \mathrm{NBF}_{4}\right)(0.1 \mathrm{M})$ in dimethylformamide $(\mathrm{DMF})$ was used as a supporting electrolyte with platinum wire auxiliary electrodes and carbon working electrodes. All measurements were carried out under a nitrogen atmosphere, and potentials were related to $\mathrm{an}^{+} / \mathrm{Ag}$ reference electrode. The potentials were calibrated with ferrocenium/ferrocene redox couple $\left(\mathrm{Fc}^{+} / \mathrm{Fc}\right)$. The scan rate was $0.1 \mathrm{~V} / \mathrm{s}$.

\subsection{Synthesis}

Synthesis of $\mathbf{L}^{\mathbf{S}_{\mathbf{F}}-\mathbf{H}}$

A mixture of $\mathrm{Pd}\left(\mathrm{PPh}_{3}\right)_{4} \quad(14.4 \mathrm{mg}, 0.013 \mathrm{mmol})$, 4,6-difluorobenzene-1,3-diboronicacidbis(pinacol)ester (91.5 mg, $0.25 \mathrm{mmol}), 2$-chlorobenzothiazole (127 mg, $0.75 \mathrm{mmol})$, aqueous solution of $\mathrm{Na}_{2} \mathrm{CO}_{3}(2 \mathrm{M}, 0.25 \mathrm{~mL}, 0.50 \mathrm{mmol})$, methanol $(0.5 \mathrm{~mL})$ and toluene $(2.0 \mathrm{~mL})$ was refluxed for $8 \mathrm{~h}$ under nitrogen atmosphere. The organic phase was separated and dried over $\mathrm{Na}_{2} \mathrm{SO}_{4}$. After filtration, the crude product was purified by column chromatography on silica gel using $\mathrm{CHCl}_{3}$ as an eluent to give 1,3-bis(2-benzothiazolyl)-4,6-difluorobenzene $\left(\mathbf{L}^{\mathbf{S}} \mathbf{F}-\mathbf{H}\right)$ as white solid $(72.4 \mathrm{mg}, 76 \%) .{ }^{1} \mathrm{H}$ NMR $\left(400 \mathrm{MHz}, \mathrm{CDCl}_{3}\right) 9.47(\mathrm{t}, J=8.0 \mathrm{~Hz}, 1 \mathrm{H}), 8.20(\mathrm{~d}, J=7.6 \mathrm{~Hz}, 2 \mathrm{H}), 7.98(\mathrm{~d}, J=7.6 \mathrm{~Hz}, 2 \mathrm{H}), 7.56(\mathrm{t}$, $J=5.6 \mathrm{~Hz}, 2 \mathrm{H}), 7.46(\mathrm{t}, J=5.6 \mathrm{~Hz}, 2 \mathrm{H}), 7.20(\mathrm{t}, J=10.4 \mathrm{~Hz}, 1 \mathrm{H}) .{ }^{13} \mathrm{C}\left\{{ }^{1} \mathrm{H}\right\}\left(100 \mathrm{MHz}, \mathrm{CDCl}_{3}\right): 162.3$, $\mathrm{d}, J=53.2 \mathrm{~Hz}), 159.7(\mathrm{~d}, J=49.6 \mathrm{~Hz}), 158.9(\mathrm{t}, J=15.2 \mathrm{~Hz}), 152.3,135.2(\mathrm{t}, J=15.2 \mathrm{~Hz}), 131.2(\mathrm{t}$, $J=17.2 \mathrm{~Hz}), 126.2,125.2,123.3,121.2,118.9(\mathrm{dd}, J=22.8 \mathrm{~Hz}, 15.2 \mathrm{~Hz}), 105.3(\mathrm{t}, J=104.8 \mathrm{~Hz}) .{ }^{19} \mathrm{~F}$ NMR (376 MHz, $\left.\mathrm{CDCl}_{3}\right)$ : -103.5 (s, 2F).

Synthesis of $\left[\mathbf{I r}\left(\mathbf{L}^{\left.\left.\mathbf{S}_{\mathbf{F}}\right) \mathbf{C l}_{2}\right]_{\mathbf{2}}}\right.\right.$ 
A mixture of $\mathbf{L}^{\mathbf{S}_{\mathbf{F}}-\mathbf{H}}(190 \mathrm{mg}, 0.50 \mathrm{mmol})$ and $\mathrm{IrCl}_{3} \cdot \mathrm{nH}_{2} \mathrm{O}(92.6 \mathrm{mg}, 0.25 \mathrm{mmol})$ was stirred in a 1:1 mixture of 2-methoxyethanol and 1,2-dichloroethane $(14 \mathrm{~mL})$ at $100{ }^{\circ} \mathrm{C}$ for $24 \mathrm{~h}$. After cooling to room temperature, the resulting precipitate was washed with methanol and $\mathrm{CHCl}_{3}$ to give $\left[\mathbf{I r}\left(\mathbf{L}_{\mathbf{F}} \mathbf{F}_{\mathbf{C}} \mathbf{C l}_{\mathbf{2}}\right]_{\mathbf{2}}\right.$ (140 mg, 87\%). Anal. Calcd for $\mathrm{C}_{20} \mathrm{H}_{9} \mathrm{Cl}_{2} \mathrm{~F}_{2} \mathrm{IrN}_{2} \mathrm{~S}_{2} \cdot \mathrm{H}_{2} \mathrm{O}$ : C, 36.36, H, 1.68; N, 4.24; Found: C, 36.05; H, 1.68; N, 4.06.

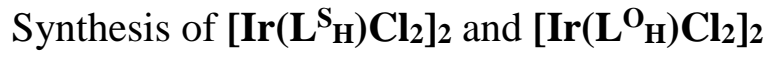

$\left[\operatorname{Ir}\left(\mathbf{L}^{\mathbf{S}_{H}}\right) \mathbf{C l}_{2}\right]_{\mathbf{2}}$ and $\left[\operatorname{Ir}\left(\mathbf{L}^{\mathbf{O}_{H}}\right) \mathbf{C l}_{2}\right]_{\mathbf{2}}$ were prepared by a similar procedure to that of $\left[\operatorname{Ir}\left(\mathbf{L}_{\mathbf{F}} \mathbf{S}_{\mathbf{F}}\right) \mathbf{C l}_{2}\right]_{\mathbf{2}}$. The products were used for following reactions without further purification and identification.

\section{Synthesis of 2}

A mixture of $\left[\mathbf{I r}\left(\mathbf{L}_{\mathbf{F}} \mathbf{S}_{\mathbf{F}} \mathbf{C l}_{\mathbf{2}}\right]_{\mathbf{2}}(20.3 \mathrm{mg}, 0.016 \mathrm{mmol})\right.$ and 2-phenylpyridine (ppy) (37.6 $\mu \mathrm{L} \mathrm{mg,} 0.26$ mmol) in ethylene glycol $(8 \mathrm{~mL})$ was stirred at $230{ }^{\circ} \mathrm{C}$ under microwave irradiation for $4 \mathrm{~min}$. After cooling to room temperature, water was added to the mixture for precipitation of the product. The resulting precipitate was collected by filtration and washed with methanol and hexane. The orange solid was extracted with $\mathrm{CHCl}_{3}$. Recrystallization by slow evaporation of the solution gave orange crystals of 2 (10.3 mg, 43\%). ${ }^{1} \mathrm{H}$ NMR (400 MHz, DMSO-d6) 9.51 (dd, $J=5.6 \mathrm{~Hz}, 1.2 \mathrm{~Hz}, 1 \mathrm{H}$, ppy), $7.72(\mathrm{~d}, J=8.4 \mathrm{~Hz}, 1 \mathrm{H}, \mathrm{ppy}), 7.59(\mathrm{td}, J=7.8 \mathrm{~Hz}, 1.2 \mathrm{~Hz}, 1 \mathrm{H}, \mathrm{ppy}), 7.34\left(\mathrm{~d}, J=7.6 \mathrm{~Hz}, 2 \mathrm{H}, \mathrm{L}_{\mathrm{F}}^{\mathrm{S}}\right), 7.19$ $(\mathrm{td}, J=5.6 \mathrm{~Hz}, 1.2 \mathrm{~Hz}, 1 \mathrm{H}, \mathrm{ppy}), 6.93(\mathrm{dd}, J=7.6 \mathrm{~Hz}, 1.2 \mathrm{~Hz}, 1 \mathrm{H}, \mathrm{ppy}), 6.75\left(\mathrm{t}, J_{H-F}=10.8 \mathrm{~Hz}, 1 \mathrm{H}\right.$, $\left.\mathrm{L}_{\mathrm{F}}^{\mathrm{S}}\right), 6.58\left(\mathrm{td}, J=8.4 \mathrm{~Hz}, 0.8 \mathrm{~Hz}, 2 \mathrm{H}, \mathrm{L}_{\mathrm{F}}^{\mathrm{S}}\right), 6.38\left(\mathrm{td}, J=8.4 \mathrm{~Hz}, 1.2 \mathrm{~Hz}, 2 \mathrm{H}, \mathrm{L}_{\mathrm{F}}^{\mathrm{S}}\right), 5.80(\mathrm{td}, J=7.2 \mathrm{~Hz}$, $1.2 \mathrm{~Hz}, 1 \mathrm{H}, \mathrm{ppy}), 5.71(\mathrm{td}, J=7.6 \mathrm{~Hz}, 1.6 \mathrm{~Hz}, 1 \mathrm{H}, \mathrm{ppy}), 5.53\left(\mathrm{~d}, J=8.4 \mathrm{~Hz}, 2 \mathrm{H}, \mathrm{L}_{\mathrm{F}}^{\mathrm{S}}\right), 4.88(\mathrm{dd}, J=$ 7.2 H, $1.2 \mathrm{~Hz}, 1 \mathrm{H}$, ppy). ${ }^{19} \mathrm{~F}$ NMR (376 MHz, $\left.\mathrm{CDCl}_{3}\right)-101.2$ (s, 2F). ESI-MS Calcd for $\mathrm{C}_{31} \mathrm{H}_{17} \mathrm{~F}_{2} \mathrm{IrN}_{3} \mathrm{~S}_{2}$ $[\mathrm{M}-\mathrm{Cl}]^{+}$726.0, Found 726.0. Anal. Calcd for $\mathrm{C}_{31} \mathrm{H}_{17} \mathrm{ClF}_{2} \mathrm{IrN}_{3} \mathrm{~S}_{2} \cdot \mathrm{CHCl}_{3}$ : C, 43.64; H, 2.06; N, 4.77; Found: C, 43.39; H, 2.01; N, 4.82 .

\section{Synthesis of $\mathbf{3}$}

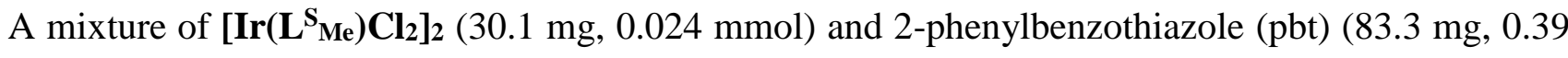
$\mathrm{mmol})$ in ethylene glycol $(8 \mathrm{~mL})$ was stirred at $230{ }^{\circ} \mathrm{C}$ under microwave irradiation for $4 \mathrm{~min}$. After cooling to room temperature, water was added to the mixture for precipitation of the product. The 
resulting precipitate was collected by filtration and washed with methanol and hexane. Recrystallization from $\mathrm{CHCl}_{3} /$ diethylether gave 3 (16.8 mg, 43\%). ${ }^{1} \mathrm{H} \mathrm{NMR}\left(400 \mathrm{MHz}, \mathrm{CDCl}_{3}\right): \delta$ $10.20(\mathrm{~d}, J=8.0 \mathrm{~Hz}, 1 \mathrm{H}, \mathrm{pbt}), 8.15(\mathrm{~d}, J=8.0 \mathrm{~Hz}, 1 \mathrm{H}, \mathrm{pbt}), 7.71-7.66\left(\mathrm{~m}, 3 \mathrm{H}, \mathrm{L}_{\mathrm{Me}}^{\mathrm{S}}\right.$ and pbt), $7.64(\mathrm{t}$, $J=7.6 \mathrm{~Hz}, 1 \mathrm{H}, \mathrm{pbt}), 7.45(\mathrm{~d}, J=7.6 \mathrm{~Hz}, 1 \mathrm{H}, \mathrm{pbt}), 7.16\left(\mathrm{t}, J=8.0 \mathrm{~Hz}, 2 \mathrm{H}, \mathrm{L}_{\mathrm{Me}}^{\mathrm{S}}\right), 7.06\left(\mathrm{~s}, 1 \mathrm{H}, \mathrm{L}_{\mathrm{Me}}^{\mathrm{S}}\right)$, $6.94\left(\mathrm{~d}, J=8.8 \mathrm{~Hz}, 2 \mathrm{H}, \mathrm{L}_{\mathrm{Me}}^{\mathrm{S}}\right), 6.91\left(\mathrm{~d}, J=8.0 \mathrm{~Hz}, 2 \mathrm{H}, \mathrm{L}_{\mathrm{Me}}^{\mathrm{S}}\right), 6.63(\mathrm{t}, J=7.2 \mathrm{~Hz}, 1 \mathrm{H}, \mathrm{pbt}), 6.54(\mathrm{t}, J=$ $7.2 \mathrm{~Hz}, 1 \mathrm{H}, \mathrm{pbt}), 5.88$ (d, J=7.6 Hz, 1H, pbt), 2.94 (s, 6H, $\mathrm{CH}_{3}$ ). ESI-MS Calcd for $\mathrm{C}_{35} \mathrm{H}_{23} \mathrm{IrN}_{3} \mathrm{~S}_{3}[\mathrm{M}-$ $\mathrm{Cl}^{+}$774.1, Found 774.2. Anal. Calcd for $\mathrm{C}_{35} \mathrm{H}_{23} \mathrm{IrN}_{3} \mathrm{~S}_{3} \mathrm{Cl}$ : C, 51.94; H, 2.86; N, 5.19; Found: C, 51.60; H, 2.90; N, 5.15.

\section{Synthesis of $\mathbf{4}$}

A mixture of $1(11.3 \mathrm{mg}, 0.015 \mathrm{mmol})$ and AgOTf $(7.7 \mathrm{mg}, 0.030 \mathrm{mmol})$ in acetonitrile $(4.3 \mathrm{~mL})$ was stirred at $80{ }^{\circ} \mathrm{C}$ for $3 \mathrm{~h}$. In the other vessel, a mixture of phenylacetylene $(6.1 \mathrm{mg}, 0.060 \mathrm{mmol})$ and $\mathrm{KOH}(1.7 \mathrm{mg}, 0.030 \mathrm{mmol})$ in anhydrous methanol was stirred at room temperature for $30 \mathrm{~min}$. To the mixture, a solution of the Ir complex was added dropwise at room temperature. After stirring at $63{ }^{\circ} \mathrm{C}$ for $2 \mathrm{~h}$, the precipitates were collected by filtration and washed with methanol and diethyl ether. The remained solid was extracted with $\mathrm{CHCl}_{3}$ and dried over $\mathrm{Na}_{2} \mathrm{SO}_{4}$. Recrystallization from $\mathrm{CHCl}_{3} /$ hexane gave 4 (10.2 mg, 83\%). ${ }^{1} \mathrm{H} \mathrm{NMR}$ (400 MHz, $\mathrm{CDCl}_{3}$ ): 10.94 (d, J= $4.8 \mathrm{~Hz}, 1 \mathrm{H}$, ppy), 8.09 (d, $J=4.0 \mathrm{~Hz}, 2 \mathrm{H}, \mathrm{ppy}), 7.71-7.7 .66\left(\mathrm{~m}, 3 \mathrm{H}, \mathrm{L}_{\mathrm{Me}}^{\mathrm{S}}\right.$ and ppy), 7.54 (d, J=8.0 Hz, 1H, ppy), 7.19 $\left(\mathrm{t}, J=7.4 \mathrm{~Hz}, 2 \mathrm{H}, \mathrm{L}_{\mathrm{Me}}^{\mathrm{S}}\right), 7.03\left(\mathrm{~d}, J=7.6 \mathrm{~Hz}, 2 \mathrm{H}, \mathrm{L}_{\mathrm{Me}}^{\mathrm{S}}\right), 6.99\left(\mathrm{~s}, 1 \mathrm{H}, \mathrm{L}_{\mathrm{Me}}^{\mathrm{S}}\right), 6.94(\mathrm{~s}, 5 \mathrm{H}$, phenylacetylene), $6.71\left(\mathrm{~d}, J=8.0 \mathrm{~Hz}, 2 \mathrm{H}, \mathrm{L}_{\mathrm{Me}}^{\mathrm{S}}\right), 6.66(\mathrm{t}, J=7.4 \mathrm{~Hz}, 1 \mathrm{H}, \mathrm{ppy}), 6.57$ (t, $\left.J=7.0 \mathrm{~Hz}, 1 \mathrm{H}, \mathrm{ppy}\right), 5.86(\mathrm{~d}, J=$ $7.2 \mathrm{~Hz}, 1 \mathrm{H}, \mathrm{ppy}), 2.94$ (s, 6H, $\mathrm{CH}_{3}$ ). ESI-MS Calcd for $\mathrm{C}_{33} \mathrm{H}_{23} \mathrm{IrN}_{3} \mathrm{~S}_{2}[\mathrm{M}-\mathrm{CCPh}]^{+}$718.09, Found 718.07. Anal. Calcd for $\mathrm{C}_{41} \mathrm{H}_{28} \mathrm{IrN}_{3} \mathrm{~S}_{2} \cdot \mathrm{CHCl}_{3}: \mathrm{C}, 53.76 ; \mathrm{H}, 3.11 ; \mathrm{N}, 4.48 ;$ Found: $\mathrm{C}, 53.44 ; \mathrm{H}, 3.78 ; \mathrm{N}$, 4.23 .

\section{Synthesis of 5}

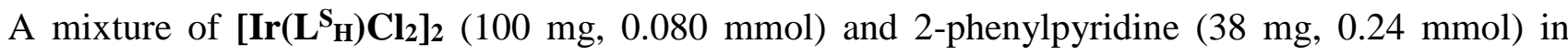
glycerol $(20 \mathrm{~mL})$ was heated by a microwave-assisted irradiation $(650 \mathrm{~W}$, multimode) for $3 \mathrm{~min}$. After cooling to room temperature, water was added to the mixture to give brown precipitate, which was collected by filtration. The crude product was purified by silica gel column chromatography with 
$\mathrm{CH}_{2} \mathrm{Cl}_{2} / \mathrm{MeOH}(25: 1 \mathrm{v} / \mathrm{v})$ as an eluent. Orange band was collected. (6 mg, $5 \%$ ). ${ }^{1} \mathrm{H}$ NMR (500 MHz, $\left.\mathrm{CDCl}_{3}\right): \delta 10.66(\mathrm{~d}, J=5.2 \mathrm{~Hz}, 1 \mathrm{H}, \mathrm{ppy}), 8.16(\mathrm{~m}, 2 \mathrm{H}, \mathrm{ppy}), 7.96\left(\mathrm{~d}, J=7.4 \mathrm{~Hz}, 2 \mathrm{H}, \mathrm{L}_{\mathrm{H}}^{\mathrm{S}}\right), 7.76(\mathrm{t}, J=$ $7.0 \mathrm{~Hz}, 1 \mathrm{H}, \mathrm{ppy}), 7.71\left(\mathrm{~d}, J=8.0 \mathrm{~Hz}, 2 \mathrm{H}, \mathrm{L}_{\mathrm{H}}^{\mathrm{S}}\right), 7.54(\mathrm{~d}, J=6.9 \mathrm{~Hz}, 1 \mathrm{H}, \mathrm{ppy}), 7.46$ (t, $J=7.4 \mathrm{~Hz}, 1 \mathrm{H}$, $\left.\mathrm{L}_{\mathrm{H}}^{\mathrm{S}}\right), 7.22\left(\mathrm{t}, J=7.4 \mathrm{~Hz}, 2 \mathrm{H}, \mathrm{L}_{\mathrm{H}}\right), 7.05\left(\mathrm{t}, J=7.4 \mathrm{~Hz}, 2 \mathrm{H}, \mathrm{L}_{\mathrm{H}}^{\mathrm{S}}\right), 6.64(\mathrm{t}, J=6.9 \mathrm{~Hz}, 1 \mathrm{H}, \mathrm{ppy}), 6.55(\mathrm{~d}$, $\left.J=7.7 \mathrm{~Hz}, 2 \mathrm{H}, \mathrm{L}_{\mathrm{H}}^{\mathrm{S}}\right), 6.51(\mathrm{t}, J=7.2 \mathrm{~Hz}, 1 \mathrm{H}, \mathrm{ppy}), 5.76(\mathrm{~d}, J=8.0 \mathrm{~Hz}, 1 \mathrm{H}, \mathrm{ppy})$. ESI-MS Calcd for $\mathrm{C}_{31} \mathrm{H}_{19} \mathrm{IrN}_{3} \mathrm{~S}_{2}[\mathrm{M}-\mathrm{Cl}]^{+}$690.0, Found 690.06. Anal. Calcd for $\mathrm{C}_{31} \mathrm{H}_{19} \mathrm{IrN}_{3} \mathrm{~S}_{2} \mathrm{Cl}: \mathrm{C}, 51.34 ; \mathrm{H}, 2.64 ; \mathrm{N}$, 5.79; Found: C, 51.50; H, 2.53; N, 6.00 .

Synthesis of 6

A mixture of [ $\left.\mathbf{I r}\left(\mathbf{L}^{\mathbf{0}} \mathbf{H}\right) \mathbf{C l}_{2}\right]_{2}$ (204 mg, $\left.0.18 \mathrm{mmol}\right)$ and 2-phenylpyridine (60 mg, $\left.0.39 \mathrm{mmol}\right)$ in glycerol (5 mL) was irradiated in a microwave $(650 \mathrm{~W}$, multimode) for $5 \mathrm{~min}$. After cooling to room temperature, water was added to the mixture to give yellowish brown precipitate. The resulting precipitate was collected by filtration and washed with methanol and hexane. The purification was performed by silica gel column chromatography with $\mathrm{CH}_{2} \mathrm{Cl}_{2} / \mathrm{MeOH}(25: 1 \mathrm{v} / \mathrm{v})(6.2 \mathrm{mg}, 5 \%)$. ${ }^{1} \mathrm{H}$ NMR (500 MHz, $\left.\mathrm{CDCl}_{3}\right): \delta 10.51(\mathrm{~d}, J=5.2 \mathrm{~Hz}, 1 \mathrm{H}, \mathrm{ppy}), 8.13(\mathrm{~m}, J=8.6 \mathrm{~Hz}, 2 \mathrm{H}, \mathrm{ppy}), 8.03$ (d, $J$ $\left.=8.0 \mathrm{~Hz}, 2 \mathrm{H}, \mathrm{L}_{\mathrm{H}}^{\mathrm{o}}\right), 7.67\left(\mathrm{~m}, 1 \mathrm{H}, \mathrm{L}_{\mathrm{H}}^{\mathrm{o}}\right), 7.56(\mathrm{~d}, J=7.4 \mathrm{~Hz}, 1 \mathrm{H}, \mathrm{ppy}), 7.51\left(\mathrm{~m}, 3 \mathrm{H}_{,} \mathrm{L}^{\mathrm{o}} \mathrm{H}\right.$ and ppy), 7.25 $\left(\mathrm{t}, J=8.0 \mathrm{~Hz}, 1 \mathrm{H}, \mathrm{L}^{\circ} \mathrm{H}\right), 7.08\left(\mathrm{t}, J=7.4 \mathrm{~Hz}, 2 \mathrm{H}, \mathrm{L}_{\mathrm{H}}^{\mathrm{o}}\right), 6.72(\mathrm{t}, J=8.0 \mathrm{~Hz}, 1 \mathrm{H}, \mathrm{ppy}), 6.51(\mathrm{t}, J=7.4 \mathrm{~Hz}$, $1 \mathrm{H}$, ppy), $6.32\left(\mathrm{~d}, J=8.0 \mathrm{~Hz}, 2 \mathrm{H}, \mathrm{L}_{\mathrm{H}}^{\mathrm{H}}\right), 5.74\left(\mathrm{~d}, J=7.4 \mathrm{~Hz}, 1 \mathrm{H}\right.$, ppy). ESI-MS Calcd for $\mathrm{C}_{31} \mathrm{H}_{19} \mathrm{IrN}_{3} \mathrm{O}_{2}$ $[\mathrm{M}-\mathrm{Cl}]^{+}$658.1, Found 658.0. Anal. Calcd for $\mathrm{C}_{31} \mathrm{H}_{19} \mathrm{IrN}_{3} \mathrm{O}_{2} \mathrm{Cl} \cdot \mathrm{H}_{2} \mathrm{O}: \mathrm{C}, 52.35 ; \mathrm{H}, 2.98 ; \mathrm{N}, 5.91$; Found: C, 52.09; H, 2.83; N, 5.31. 
Table 3 Crystal Data and Details of Structure Refinement.

\begin{tabular}{|c|c|c|c|}
\hline & 2 & 3 & 4 \\
\hline Formula & $\begin{array}{l}\mathrm{C}_{31} \mathrm{H}_{17} \mathrm{~N}_{3} \mathrm{~F}_{2} \mathrm{~S}_{2} \mathrm{ClIr} \\
\mathrm{CHCl}_{3}\end{array}$ & $\mathrm{C}_{35} \mathrm{H}_{23} \mathrm{~N}_{3} \mathrm{~S}_{3} \mathrm{ClIr}$ & $\begin{array}{l}\mathrm{C}_{41} \mathrm{H}_{28} \mathrm{~N}_{3} \mathrm{~S}_{2} \mathrm{Ir} \\
\mathrm{CHCl}_{3}\end{array}$ \\
\hline Formula weight & 880.66 & 809.44 & 938.41 \\
\hline Crystal size, $\mathrm{mm}$ & $0.095 \times 0.052 \times 0.020$ & $0.160 \times 0.110 \times 0.060$ & $0.070 \times 0.051 \times 0.023$ \\
\hline Crystal system & monoclinic & orthorhombic & triclinic \\
\hline Space group & $\mathrm{P} 21 / \mathrm{n}$ & Pbca & $\mathrm{P}-1$ \\
\hline$a, \AA$ & $9.7605(11)$ & $14.746(3)$ & $11.8261(14)$ \\
\hline$b, \AA$ & $12.8784(15)$ & $16.141(4)$ & $12.4993(15)$ \\
\hline$c, \AA$ & $23.691(3)$ & $25.413(6)$ & $13.8285(17)$ \\
\hline$\alpha, \operatorname{deg}$ & & & $111.8740(10)$ \\
\hline$\beta, \operatorname{deg}$ & $91.327(2)$ & & $107.4210(10)$ \\
\hline$\gamma, \operatorname{deg}$ & & & $93.6320(10)$ \\
\hline$V\left(\AA^{3}\right)$ & 2977.2(6) & $6049(3)$ & $1774.3(4)$ \\
\hline$Z$ & 4 & 8 & 2 \\
\hline$\mu, \mathrm{cm}^{-1}$ & 50.39 & 47.54 & 41.53 \\
\hline$F(000)$ & 1704 & 3184 & 924 \\
\hline Dcalcd, $\mathrm{g} \mathrm{cm}^{-3}$ & 1.965 & 1.782 & 1.756 \\
\hline No. of date & 16185 & 31979 & 20091 \\
\hline No. of unique date & 6513 & 6660 & 7741 \\
\hline No. of variables & 397 & 262 & 456 \\
\hline$R(I>2 \mathrm{~s}[I])$ & 0.0394 & 0.0264 & 0.0389 \\
\hline$R 1$ (All reflections) & 0.0792 & 0.0380 & 0.0515 \\
\hline$R w($ All reflections $)$ & 0.0793 & 0.0696 & 0.0877 \\
\hline GOF & 0.96 & 1.037 & 1.026 \\
\hline
\end{tabular}




\section{Acknowledgement}

The authors thank to the Chemical Analysis Center of University of Tsukuba for the measurements of NMR, elemental analysis, and X-ray diffraction. Prof. T. Nabeshima and Prof. M. Yamamura are grateful for the support of quantum yield measurements. We acknowledge Mr. S. Kobayashi and K. Nakamura for their experimental supports. E. S. and M. H. acknowledge Prof. Koichi Nozaki at University of Toyama for the photophysical measurements, and Dr. Yoshiaki Tanabe, Dr. Shintaro Kodama and Prof. Youichi Ishii at Chuo University for the X-ray structure analysis.

\section{Appendix A. Supplementary data}

Supplementary data related to this article can be found at http:// dx.doi.org.

\section{References}

[1] M. Albrecht, G. van Koten, Angew. Chem. Int. Ed. 40 (2001) 3750-3781.

[2] J.A.G. Williams, Chem. Soc. Rev. 38 (2009) 1783-1801.

[3] G. Van Koten, J. Organomet. Chem. 730 (2013) 156-164.

[4] C. Gunanathan, D. Milstein, Chem. Rev. 114 (2014) 12024-12087.

[5] K. Okamoto, J. Kuwabara, T. Kanbara, Chem. Lett. 44 (2015) 102-110.

[6] J. Kalinowski, V. Fattori, M. Cocchi, J.A.G. Williams, Coord. Chem. Rev. 255 (2011) 24012425 .

[7] A.J. Wilkinson, A.E. Goeta, C.E. Foster, J.A.G. Williams, Inorg. Chem. 43 (2004) 65136515.

[8] A.J. Wilkinson, H. Puschmann, J.A.K. Howard, C.E. Foster, J.A.G. Williams, Inorg. Chem. 45 (2006) 8685-8699.

[9] V.L. Whittle, J.A.G. Williams, Inorg. Chem. 47 (2008) 6596-6607.

[10] L.F. Gildea, A.S. Batsanov, J.A.G. Williams, Dalt. Trans. 42 (2013) 10388-10393.

[11] T. Yutaka, S. Obara, S. Ogawa, K. Nozaki, N. Ikeda, T. Ohno, Y. Ishii, K. Sakai, M.A. Haga, Inorg. Chem. 44 (2005) 4737-4746.

[12] S. Obara, M. Itabashi, F. Okuda, S. Tamaki, Y. Tanabe, Y. Ishii, Inorg. Chem. 45 (2006) 8907-8921.

[13] L. Yang, F. Okuda, K. Kobayashi, K. Nozaki, Y. Tanabe, Y. Ishii, M.A. Haga, Inorg. Chem. 47 (2008) 7154-7165.

[14] M. Ashizawa, L. Yang, K. Kobayashi, H. Sato, A. Yamagishi, F. Okuda, T. Harada, R. Kuroda, M.-A. Haga, Dalt. Trans. (2009) 1700-1702.

[15] C. Adachi, M.A. Baldo, M.E. Thompson, S.R. Forrest, J. Appl. Phys. 90 (2001) 5048-5051. 
[16] S. Lamansky, P. Djurovich, D. Murphy, F. Abdel-Razzaq, H.E. Lee, C. Adachi, P.E. Burrows, S.R. Forrest, M.E. Thompson, J. Am. Chem. Soc. 123 (2001) 4304-4312.

[17] A. Tsuboyama, H. Iwawaki, M. Furugori, T. Mukaide, J. Kamatani, S. Igawa, T. Moriyama, S. Miura, T. Takiguchi, S. Okada, M. Hoshino, K. Ueno, J. Am. Chem. Soc. 125 (2003) 12971-12979.

[18] Y. Koga, M. Kamo, Y. Yamada, T. Matsumoto, K. Matsubara, Eur. J. Inorg. Chem. (2011) 2869-2878.

[19] N. Darmawan, C.H. Yang, M. Mauro, M. Raynal, S. Heun, J. Pan, H. Buchholz, P. Braunstein, L. De Cola, Inorg. Chem. 52 (2013) 10756-10765.

[20] C.-Y. Kuei, S.-H. Liu, P.-T. Chou, G.-H. Lee, Y. Chi, Dalt. Trans. 45 (2016) 15364-15373.

[21] D. Choi, T. Kim, S.M. Reddy, J. Kang, Inorg. Chem. Commun. 12 (2009) 41-44.

[22] J. Kuwabara, T. Namekawa, M. Haga, T. Kanbara, Dalt. Trans. 41 (2012) 44-46.

[23] P. Brulatti, R.J. Gildea, J.A. Howard, V. Fattori, M. Cocchi, J.A. Williams, Inorg Chem 51 (2012) 3813-3826.

[24] J. Lin, N.Y. Chau, J.L. Liao, W.Y. Wong, C.Y. Lu, Z.T. Sie, C.H. Chang, M.A. Fox, P.J. Low, G.H. Lee, Y. Chi, Organometallics 35 (2016) 1813-1824.

[25] C.Y. Kuei, W.L. Tsai, B. Tong, M. Jiao, W.K. Lee, Y. Chi, C.C. Wu, S.H. Liu, G.H. Lee, P.T. Chou, Adv. Mater. 28 (2016) 2795-2800.

[26] H. Konno, Y. Sasaki, Chem. Lett. 32 (2003) 252-253.

[27] L. Murphy, P. Brulatti, V. Fattori, M. Cocchi, J.A.G. Williams, Chem. Commun. 48 (2012) 5817-5819. 
Graphical abstract

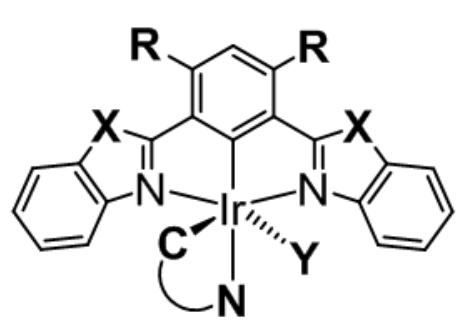

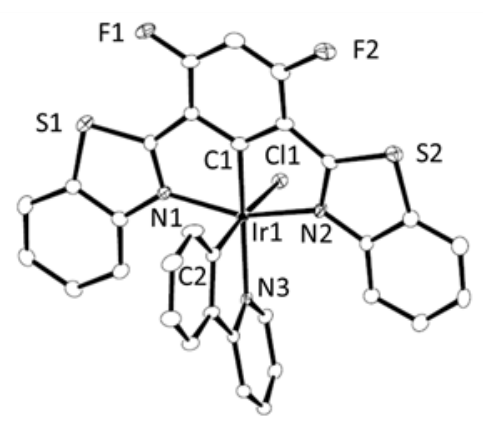

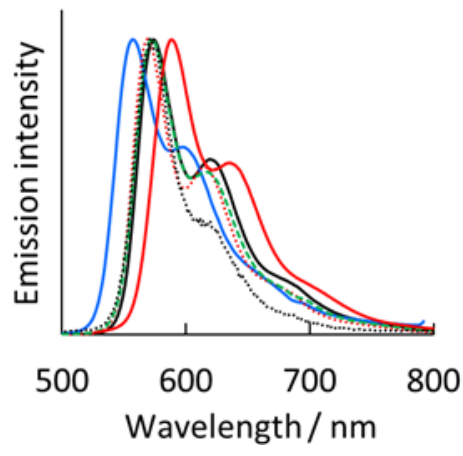

Synopsis

This paper discloses crystal structures and photophysical properties of $\operatorname{Ir}(\mathrm{III})$ complexes bearing benzothiazole or benzoxazole-based NCN pincer ligands, bidentate NC ligands, and ancillary ligands. The structure of the NCN pincer ligands is a dominant factor for modulating emission wavelength. The OLEDs with the Ir complex showed electroluminescence with 14\% external quantum efficiency.

Research highlights

A highly emissive Ir complexes with pincer lingads

Relation of chemical structure and physical property

Electroluminescence in OLEDs 